\title{
External and Internal: Absolute and Relative Space in Song Literati Painting
}

In an essay on painting Bai Juyi (772-846) remarked "There is no constant standard in painting; painting takes resemblance as its standard; there is no con-

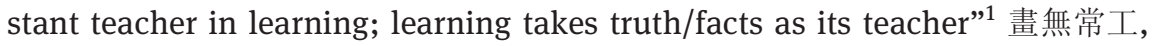
以似為工, 學無常師, 以真為師. Resemblance and facts both point to external reality as the standard, as opposed to medieval dogma or hereditary rank. From the ninth century through the eleventh, facts slowly became the normative standard in civil service examinations, in policy debate, and in pictorial art. Speaking of the New Policy reforms toward the end of the Northern Song (960-1127), Peter Bol observed:

The policies themselves aimed to integrate the energies of a dynamic society and encour-
age economic growth. Rather than stabilizing the social order it expanded opportunities
and through education enlarged the pool of talent that could serve in government. More-
over, it aimed to make use of the increase in wealth, the spread of education, and the
development of the south to lessen inequalities, not to defend privilege . . . it was a gov-
ernment that believed that if people were properly educated, they too, like the ideologi-
cally-driven policy makers, would see that the policies were fundamentally correct and
fully grounded in reality.
(emphasis added)

One manifestation of reality-based representation was a consistent horizon in landscape painting. Even in long handscrolls, the horizon doesn't waver, any more than it would in real life. It is this that creates in Northern Song landscape the illusion of spatial depth. In Northern Song literati painting however, the horizon disappears. In its place we find lines of sight, and sometimes multiple and contradictory lines of sight within a single scene. Such practices signal a complete rejection of spatial depth, for the horizon takes the external world as its reference, while line-of-sight privileges the artist's subjective point of view. This does not imply that literati artists rejected reality or facts; it is simply that they drew attention to a different, and equally real set of facts. Adopting a social and epistemological perspective, this paper examines the profound implications of the shift in pictorial space from horizon to line-of-sight, and by

1 Bai Juyi, Ji hua (A Record of Painting), Zhang Chunlin 张春林 ed., Baijuyi quanji (Collected works of Bai Juyi) (Beijing: Zhongguo wenshi chubanshe, 1996), 755-756.

2 Peter Bol, "Whither the Emperor: Emperor Huizong, the New Policies, and the Tang-Song Transition” The Journal of Song-Yuan Studies 31 (2001), 103-134, reference, 132-133.

Ә Open Access. ( 2022 Martin J. Powers, published by De Gruyter. (c) BY-NC-ND This work is licensed under the Creative Commons Attribution-NonCommercial-NoDerivatives 4.0 International License. https://doi.org/10.1515/9783110749823-002 
extension, as explored in Ping Foong's and Daniel Morgan's essays, the effect of political power in the representation of the external world.

\section{Style and epistemology}

Heinrich Wölfflin (1864-1945), the "father" of modern art history, observed a hundred years ago that the range of information available to vision far outstrips what an artist can copy with pigments. Wölfflin understood that this limitation explained the origins and necessity of style, for there could never be a style that perfectly described nature. As a result, even if an artist's aim were to transcribe real appearances as faithfully as possible, s/he would be forced to adopt a style that privileged some kinds of information over others. Wölfflin's student Ludwig Bachhofer (1894-1976) pressed this insight further, observing that style is a filter that encodes a particular set of priorities. In other words, style is a function of epistemology: "No less ambiguous is the term 'stylization.' Those who use it are often apt to forget that a drawing by Rembrandt is as 'stylized' as one by an Egyptian painter . . . The reason is that different times have different ideas about what is accidental and what is basic."3

This consideration prompts the more general postulate that, in pictorial art, the treatment of space is contingent upon specific epistemological assumptions. It is not merely a matter of accuracy or skill. What information gets included depends upon what a particular visual community regards as significant knowledge. I make no claim to novelty here. Referring to the medieval windows in Canterbury Cathedral, Norman Bryson presumed that medieval styles were adapted to the conveyance of textual doctrine at the expense of descriptive detail: "By the 'discursive' aspect of an image, I mean those features which show the influence over the image of language - in the case of the window at Canterbury, the Biblical texts which precede it and on which it depends, the inscriptions it contains within itself to tell us how to perceive the different panels." ${ }^{4}$ Bryson argued that medieval artists tended to suppress "irrelevant" visual details such as light, the time of day, the weight of cloth, or other accidents of the moment in favor of the textual message. What is most legible therefore are those "discursive" aspects of the image relating to Church dogma.

3 Ludwig Bachhofer, A Short History of Chinese Art (New York, 1946), 86.

4 Norman Bryson, Word and Image: French Painting of the Ancien Regime (Cambridge, 1980), 1-9. 
On the other hand, in both China and Europe, early modern styles provide a rich range of information about the passage of time, whether it is the season, the time of day, or the effects of time on objects via wind, rain, and other forms of erosion. Artists in both China and Europe, moreover, adopted similar methods for representing deep space convincingly: the representation of objects according to scale; the diminution of size in accordance with distance from the picture plane; the use of atmospheric perspective; the use of a repoussoir to serve as a scale for distance, and so on. All of these techniques ensure that viewers of such paintings would become aware of the passage of time, as well as the relative height of objects, or the distances between them. ${ }^{5}$

One might be tempted to formulate a simple binary: less developed, premodern societies that prioritize social status or dogma over facts tend to favor simplified shapes, outlines, colors, and flattened space, while more modern, reality-based societies favor naturalistic representation. Unfortunately, matters are not so simple. Mao's China was certainly "modern” in the sense that it was industrialized and made use of modern administrative, military, and propaganda techniques, yet the favored style for poster art significantly reduced texture, simplified outlines, flattened color, and overall reduced descriptive detail so as to highlight textual doctrines that, often enough, were placed directly onto the poster. This description, moreover, could apply to a great many posters, from those of Toulouse-Lautrec to the iconic Obama posters of only a few years back. We must conclude then, that attention to time and space in pictorial art is not a matter of primitive versus advanced, or premodern versus modern. Whenever the discursive dimension is dominant, as in poster art, artists may reduce information about the changing conditions of real things so as to privilege a verbal message whose content is so important as to eclipse any incidental, factual, details.

Likewise, while literati painting abandoned the consistent use of horizon, atmospheric perspective, light, or the depiction of objects to scale, literati artists continued to place great value upon facts, and time. In literati painting the facts were personal facts, such as the marks made by the artist's brush, the choice of style, literary citations or other personal interventions the artist might make. As a result, Time remained a factor in literati painting, every bit as much as in naturalistic work. ${ }^{6}$ The brushstroke, after all, was a direct record of the

5 Martin Powers, "Picturing Time in Song Painting and Poetry", in Joseph Lam et. al., eds., The Senses of the City: Perceptions of Hangzhou and Southern Song China, 1127-1279 (Hong Kong: Hong Kong University Press, 2016), 55-72.

6 Martin Powers, "The Temporal Logic of Citation in Chinese Art," Art History, vol. 37, no. 4 (September, 2014), 745-763. 
artist's movement over a specific period of time, whose speed and force could be inferred from the length and character of the brush mark. In the same way, references to historically defunct styles, when juxtaposed with contemporary styles, necessarily called to mind the passage of historical time. Unlike some political posters moreover, a literati painting made no timeless assertions. The main difference between literati landscapes and the naturalistic landscapes is that the latter convey publicly visible facts while the former convey personal, yet still sharable facts. These facts can be shared, however, only when the artist chooses to do so, whereas a mountain range can be assessed any time, so long as you are standing in the right place.

\section{Facts and meritocracy}

The literati decision to prioritize personal facts over publicly observable facts is understandable if we consider that the term for facts, shi 實, featured prominently in debates over meritocratic appointment. In a meritocratic system, men are chosen for public office according to the facts of their individual performance on examinations, or in office. During China's medieval period however, family lineage generally trumped facts in the assignment of office. True, Empress Wu Zetian (624-705) had revived and improved the examinations with a view to making room for talented men of ordinary birth, but in Tang times the examinations were not anonymous, so the aristocracy readily found ways to rig the system in their favor. As a result, the vast majority of appointments, especially for high office, went to men of noble lineage. This situation came under challenge in the first half of the eighth century when Li Ang was appointed as chief examiner. He objected to the fact that most of the appointments conferred previously, in his view, were merely decorative/shi 飾 and without substance/ shi 實. $^{7}$ What did he mean by that?

The semantic range of shi at that time encompassed "real," "actual," "factual," and just plain facts. Li Ang contrasted this with shi, which implied useless ornament, empty display, or baseless claims. Li was determined to replace shi with shí, and so he issued orders that the grade assigned was to be based on the actual quality of the examination. ${ }^{8}$ The source for this language was

7 以舉人皆飾名求稱, 搖蕩主司, 談毀失實, 窭病之而將革焉。Cited in Li Shu 李樹, Zhongguo keju shihua (中國科舉史話 A history of China’s civil service examination) Jinan: Qilu shushe 2007, 14.

8 Li, Zhongguo keju shihua, 14. 
classical bureaucratic theory. One branch of that theory, called mingshi theory, laid out procedures for appointing competent officials. Each office title, or ming, would be defined by a specific charge with powers limited to those required to fulfil its charge. If a man was thought suitable for an office, he would be assigned to it, and his actual/shí performance would be compared with his charge/ming. If the two matched, he would retain his title; if not, he would be dismissed. ${ }^{9}$

Li Ang in essence applied these classical principles to the grading of examinations so that the grade assigned would match the candidate's actual performance. Such reforms eventually made it possible for men of more ordinary lineage, such as Han Yu (768-824) or Bai Juyi, to acquire office via the examinations. ${ }^{10}$ Not surprisingly Bai and his friends were highly conscious of the struggle between privilege and merit. In fact, they called explicitly for the overthrow of the aristocratic system and its replacement with a meritocratic administration. ${ }^{11}$ This meant, in effect, rejecting the authority of the sage kings who, contemporaries avowed, had created the feudal system as a model for all time. Bai's friend Liu Zongyuan (773-819) deftly refuted that theory by arguing that historical change was a product of shizhilai 勢之來, the “force of circumstance," and had nothing to do with the sage kings. ${ }^{12}$ One cannot easily overstate the radical nature of this claim. It would be as if Thomas Aquinas had argued that the normative social order had nothing to do with God's will.

In keeping with these sentiments, the guwen 古文, or “plain style” intellectuals took every opportunity to promote the core significance of shí in either personal or public policy decision-making. We have seen this already in Bai's remark that "In learning, there is no constant, meaning no "single" teacher; learning takes what is true (facts) as its teacher." This would have been a radical thing to propose in any premodern society, for it meant that you cannot decide the reliability of a statement on the basis of who said it, whether that be

\footnotetext{
9 Di, Yuzhong. Zhengming: Chinese Logic (Beijing: Central Compilation and Translation Press, 2013), 36-41. Some bureaucratic theorists used “performance and title” 形名, to convey much the same idea. See Martin Powers, Pattern and Person: Ornament, Society, and Self in Classical China (Cambridge: Harvard University Press East Asian Series, 2006), 194-206.

$10 \mathrm{Li}$, Zhongguo keju shihua, 14-17.

11 Liu Zongyuan (773-819), ‘Fengjian lun', in Lü Ch’ing-fei 吕晴飞, ed., Liu Zongyuan sanwen, 3 vols., Taipei, World publishing house, 1994), I:23-32; Bai Juyi, "Yi fengjian, lun junxian (against feudalism and for salaried administration)” in Zhang Chunlin 张春林 ed., Baijuyi quanji (白居易全集 Collected works of Bai Juyi), (Beijing: Zhongguo wenshi chubanshe, 1996), 1044-1045.

12 Martin Powers, China and England: the Preindustrial Struggle for Justice in Word and Image (London: Routledge, 2018), 52-53.
} 
the sage kings, Jesus Christ, Confucius, or Mao. In the end, only the facts matter. Bai Juyi made this point more explicitly in the preface to his "New Folk Songs," a collection of his own poems castigating the abuse of the vulnerable by the nobility, the generals, the emperor, and even social convention:

Their content is plain and factual/shí, so that those who recite them will earn the trust (of their listeners); their style is easy and straightforward, so that their message may spread widely in song . . . In a word, they were composed for the ruler, for the officials, for the people, for (real) things and for (real) affairs, not for the sake of literary language! ${ }^{13}$ 其事 核而實, 使采之者傳信也。其體順而肆, 可以撥於樂章歌曲也 . . 總而言之, 為君、為臣、 為民、為物、為事而作, 不為文而作也。

The key concern in Bai's "New Folk Songs” was social reality, meaning injustice. This was primarily a question of public policy, but in matters of appointment to office, the reality at stake was the reality of an individual's learning, talent, experience, and dedication to the public good. Before the end of the Northern Song dynasty, these same criteria would be applied to literati painting.

Examinations were by nature about the individual, because the examinee's name, family background, religion, ethnicity, and personal preferences were all hidden from the examiners. This was accomplished by replacing the examinee's name with a number. Once the number was assigned, the examination text was to be copied by a scribe. The five examiners, whose grades were averaged, could not know who the author was. ${ }^{14}$ A literati painting, however, while every bit as individual as an examination text, was not anonymous. How could an artist assert his or her (yes, there were women artists) personal views in such a way that the factual traces of individuality would not be missed?

Alfreda Murck has demonstrated in rich detail how poetic practice provided a natural model for literati painters. Not only did Du Fu 杜甫 (712-770) embody the ideal of a public-spirited intellectual, he was also a master of historical and poetic citation. Rather than simply ape famous poetic phrases, as Bai Juyi had characterized the work of earlier poets, ${ }^{15} \mathrm{Du} \mathrm{Fu}$ "reworked arcane cliché's into fresh expressions, and incorporated the vernacular into classical forms." ${ }^{16}$ In

13 Bai Juyi (772-846), Bai juyi quanji (the collected works of Bai Juyi), Liu Mingjie 刘明杰, annot. (Guangzhou, Zhuhai Press, 1996), 41.

$14 \mathrm{Qu}$ Chaoli, Songdai difangzhengfu minshi shenpan zhineng yanjiu (The function of civil courts in local government in Song times) (Chengdu: Bashu Shudian, 2003), 16.

15 Bai Juyi, "Yu yuanjiu shu” (A Letter for Yuan Zhen), in Zhou Shaoliang, ed., Quan tangwen xinbian, (Collected essays from the Tang dynasty), Vol. 3, No.3 (Changchun: Jilin wenshi Press, 2000), 7622.

16 Alfreda Murck, Poetry and painting in Song China: the subtle art of dissent (Cambridge: Cambridge University Press, 2000), 53. 
other words, he "modernized" stylistically obsolete phrases by making them his own, and he mixed styles from different and incompatible genres in the same work. These qualities were especially appreciated by leading Northern Song literati: "He (Huang Tingjian) admired Du Fu's ingenuity at incorporating other poets' words and ideas into his verse and making appropriate allusions that paradoxically seemed fresh and natural."17 For the literati, "natural" was understood in the fifth-century poet Tao Yuanming’s 陶淵明 (317-420) sense, meaning according to one's own nature. ${ }^{18} \mathrm{Du}$ Fu's citations were natural precisely because he altered the reference sufficiently to mark it as originating with $\mathrm{Du}$ Fu, not with the source. Significantly, Murck demonstrates that the application of these ideals was not limited to poetry, but informed literati painting as well. Yet painting presumably presented greater challenges because of the historicity of pictorial space. In the history of painting, East and West, every pictorial style must adopt a particular set of procedures for dealing with pictorial space. Because these procedures change over time, they are specific to particular historical moments. Citing a phrase by Tao Yuanming does not require adopting his verse form, but citing a figure from the fourth-century artist $\mathrm{Gu}$ Kaizhi 顧愷之 (344-406) implies a spatial system completely different from that which was normative in Song times. How did Northern Song literati deal with this?

Here again, the late Tang guwen movement laid the foundations for Song literati practice. The key insight of the guwen movement was that human institutions are merely conventional, products of what Liu Zongyuan called "the force of circumstance" at a particular moment in history, and not the timeless inventions of the sage kings. Therefore institutions, individuals, and cultural practice all could be altered to improve social conditions in the present. Such insights into the contingency of historical institutions paved the way for heightened historical consciousness in Song times. Eventually this led to the understanding that pictorial style, too, was a product of historical circumstance and could be altered, adjusted, or cited at will. ${ }^{19}$ Despite the widely recognized achievements of Song naturalism, there was no reason why an artist could not employ multiple styles from different periods in the same scene, just as s/he

17 Murck, Poetry and Painting, 55.

18 Martin Powers, "Recurrent dialogues in the history of Chinese and English garden design," in Malcolm Baker and Andrew Hemingway, eds., Art as Worldmaking: Critical Essays on Realism and Naturalism (Manchester: Manchester University Press, 2019), 115-127, reference 119-120.

19 Martin Powers, "Imitation and Reference in China's Pictorial Tradition,” in Wu Hung, ed., Reinventing the Past: Archaism and Antiquarianism in Chinese Art and Visual Culture (Chicago: Art Media Resources, 2010), 103-126. 
could cite, within the same poem, phrases from poets who worked in different styles and periods.

The literati infringement of the standard rules for depicting form, texture, light, or space and time, has been recognized for decades. Richard Barnhart was among the first to stress the radical overthrow of Song naturalism in the reappearance of formerly defunct, prenaturalistic pictorial styles: “The Gu Kaizhi tradition of secular figure painting, in contrast, was virtually moribund in the eleventh century ... . [The] relatively primitive landscape art [of Jing Hao] had been thoroughly overshadowed by the great masters of the tenth and eleventh centuries." 20 Yet, such moribund styles reappeared in the work of the literati artist Li Gonglin 李公麟 (1049-1106). Robert Harrist likewise noted the deliberate rejection of naturalistic standards by literati artists: "it appears that Li Gonglin willfully turned his back on the Chinese landscapist's hard-won mastery of naturalistic representation in favor of an eccentric pictorial language of his own devising." 21

The key words here are "of his own devising." Nowhere in the world of the eleventh century, outside China, was an artist authorized to flaunt basic pictorial conventions, replacing accepted forms for completely eccentric forms "of his own devising." I do not refer here to the use of some novel flourish or ornament, or placing Abraham on the right side of the composition instead of the left, what historians of European art call "inventions". I am referring to the practice of breaking accepted conventions of spatial arrangement and replacing them with fundamentally different and personal modes of pictorial construction. How did this come about?

One can approach this question in two ways: 1) How did literati artists theorize these interventions into conventional style? 2) What enabled them to pursue such radical action? The first is easier to answer. Remember that Bachhofer saw every style as encoding a list of priorities. He presumed that these priorities would be those of the community for which the work had been made, for it would have been that community that gave rise, over time, to the style commonly employed by local artists or artisans. Literati painting also encoded a list of priorities, but to a significant extent these were the personal priorities of an individual master, not those of the general community. So, the question is, can

20 Richard Barnhart, "Li Kung-lin's Use of Past Styles," in Artists and Traditions: Uses of the Past in Chinese Culture, ed. Christian F. Murck (Princeton, NJ: Princeton University Press, 1976), 52.

21 Robert E. Harrist, Painting and Private Life in Eleventh-Century China: Mountain Villa by Li Gonglin (Princeton, NJ: Princeton University Press, 1998), 91. 
we find in the art theory of the Northern Song some articulation of this principle? The answer is, yes.

There were two parts to this theory. The first was the redefinition of the word for natural/ziran 自然. In the art critical writings of Dong You 董卢 (1031-1095) it is evident that most professional artists of the time used ziran to mean something like "naturalistic," a pictorial image that closely matched the appearance of real objects. Dong You, however, like other literati, regarded this process as completely "unnatural.” Dong interpreted ziran to mean "naturally." In the end, this meant to paint according to one's own, personal nature rather than following a fixed set of rules, as in the work of Tao Yuanming, or $\mathrm{Du} \mathrm{Fu} .^{22}$

This view was reinforced in the art critical essays of Shen Kuo 沈括 (1031-1099). Like Dong You, Shen rejected the idea that the business of art consisted of following a set of mechanical rules to achieve a predetermined result. Instead, what was truly wonderful about the art of painting was its capacity for shenhui 神會, or imaginative encounter. He found a model for this in a passage describing Wang Wei's (699-759) painting style. Reportedly Wang completely ignored the unity of time and space, painting plants from different seasons together in the same scene. Shen deduced from this (erroneously one suspects) that Wang wilfully created his own, personal rules, in defiance of normal pictorial convention. ${ }^{23}$ By peering at such a work, a viewer could enter into Wang Wei's alternative world in imagination: "Therefore the picture's logic enters into the imagination and returns as a natural thought."24

Such a theory would give an artist considerable license to alter conventional rules of representation. Seeing as both Dong and Shen placed high value on avoiding any appearance of mechanical obedience to rules, it would be incumbent on the artist to make evident to viewers his or her wilful interventions. Among the most effective ways to accomplish this would be to alter standard pictorial techniques for depicting space and time.

Elsewhere I have examined multiple examples of pictorial practices corresponding to these theoretical postulates. ${ }^{25}$ Many are spatial in nature, including: eliminating the horizon; raising or lowering the plane of recession arbitrarily along the length of a handscroll; flattening the winding stream used to create a sense of deep space in naturalistic painting; using multiple and conflicting lines

22 Powers, "Recurrent Dialogues," 119.

23 Powers, "Recurrent Dialogues," 119.

24 Shen Kuo, Mengxi bitan 梦溪笔谈 (Notes from the stream of dreams), vol. 3 (Yangzhou: Guangling shushe, 2003), 152.

25 Martin Powers, "The Temporal Logic of Citation in Chinese Art," Art History, vol. 37, no. 4 (September, 2014), 745-763. 
of sight within the same scene; ${ }^{26}$ or juxtaposing incompatible historical styles from different periods within the same scene. ${ }^{27}$ Among all these bold and unprecedented pictorial interventions, perhaps the use of multiple lines of sight is the most disorienting for the viewer. This device occurs in several works associated tangentially with Li Gonglin, but nowhere more startlingly than in the handscroll attributed to Qiao Zhongchang 喬仲常 (active 1120s) in the Nelson-Atkins Museum of Art. This artist employed the device twice in his scroll, in each case at a moment in the narrative where the protagonist, the poet and statesman Su Shi 蘇軾 (1037-1101), is unable to distinguish between illusion and reality.

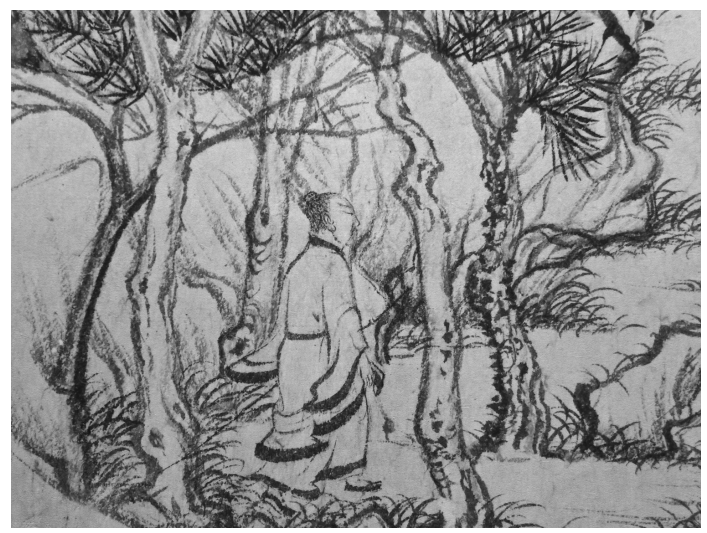

Figure 1: Su Shi ascending the mountain. Qiao Zhongchang, Chinese (active late 11th-early 12th century). Illustration to the Second Prose Poem on the Red Cliff, Northern Song Dynasty (960-1127 C.E). Handscroll, ink on paper. Image \& colophon: 12 x $2473 / 4$ inches (30.48 x $629.29 \mathrm{~cm})$. The Nelson-Atkins Museum of Art, Kansas City, Missouri. Purchase: Nelson Gallery Foundation, F80-5. Photography by the author.

In the first instance (Figure 1), Su Shi has left his companions behind; his surroundings grow increasingly strange as he climbs among eerily shaped rocks and trees to the top of a promontory. He is so high now that from that position he can peer into an eagle's nest while looking down to the rocks and waters below: "I suddenly let out a sharp cry. The plants and trees were startled and shook; mountains resounded, valleys echoed. Winds arose, and the water became agi-

26 Powers, “Temporal Logic,” 748-751.

27 Powers, “Temporal Logic," 758-761. 


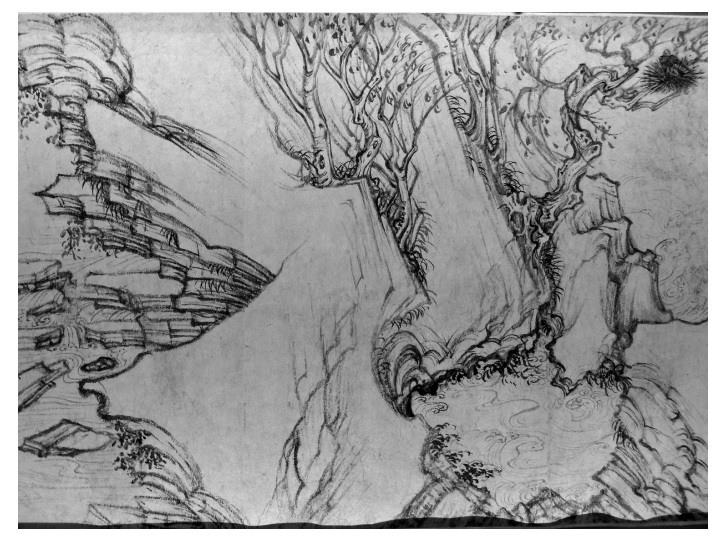

Figure 2: A view from the mountain with three, contrasting lines of sight. Qiao Zhongchang, Chinese (active late 11th-early 12th century). Illustration to the Second Prose Poem on the Red Cliff, Northern Song Dynasty (960-1127 C.E). Handscroll, ink on paper. Image \& colophon: $12 x$ 247 3/4 inches $(30.48$ x 629.29 cm). The Nelson-Atkins Museum of Art, Kansas City, Missouri. Purchase: Nelson Gallery Foundation, F80-5. Photography by the author.

tated." 28 At this stage of the poem the artist does not show us Su's image; instead he shows us what $\mathrm{Su}$ would have seen. This, the artist conveys by permitting us to look almost straight down into the roiling waters (Figure 2), yet at the same time, and from the same vantage point, we can look straight ahead at jagged rocks, with the two lines of sight crossing at almost ninety degrees. Should our gaze wander just a bit to the right, we can see other rocks in a normal threequarter view, all within the same scene, a scene that lacks any hint of a horizon. To suggest that the visual confusion the artist introduced into this scene is unrelated to the mental confusion described in Su's poem would strain credulity, but should one need more evidence, a repetition of this device occurs again in the scroll the second time that $\mathrm{Su}$ Shi finds it difficult to distinguish fact from fantasy.

This moment occurs in the penultimate scene of the scroll (Figure 3). There we simultaneously see Su Shi asleep in his bed, and sitting beside himself in a dream where he converses with a couple Daoists (Figure 4). We view both the real Su Shi and the dream Su Shi head on, but just behind the building where he sleeps we can also see his courtyard. This should have been blocked from view

28 Translation by Richard Strassberg, trans. and annot., Inscribed Landscapes: Travel Writing from Imperial China (Berkeley: University of California Press, 1994), 188. 


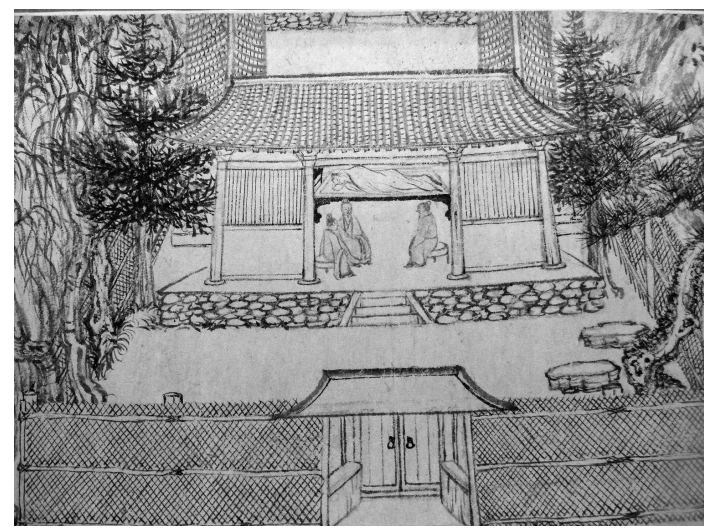

Figure 3: A view of Su Shi's cottage with the guest room courtyard behind at right angles to one another. Qiao Zhongchang, Chinese (active late 11th-early 12th century). Illustration to the Second Prose Poem on the Red Cliff, Northern Song Dynasty (960-1127 C.E). Handscroll, ink on paper. Image \& colophon: $12 \times 2473 / 4$ inches $(30.48 \times 629.29 \mathrm{~cm})$. The Nelson-Atkins Museum of Art, Kansas City, Missouri. Purchase: Nelson Gallery Foundation, F80-5. Photography by the author.

by the structure in which he sleeps, but here it appears to the scroll viewer flipped up ninety degrees so that we can look down into the courtyard at the same time that we look straight ahead at Su Shi in his dream (Figure 3). Undoubtedly Su Shi is confused at this stage in the poem and, once again, in the painting, we gaze at the scene along two lines of sight meeting at ninety degrees. In short, the painting forces us to adopt highly personal lines of sight that lead us to experience confusion akin to that of the protagonists within the poem as well as within the scroll.

Clearly there is a kind of logic to what we find here, but it is a highly personal logic peculiar to an artist who has created pictorial effects of his own devising. In this instance, achieving these effects required him to violate multiple rules of deep space representation that were widely accepted as normative at the time. Ironically, it is precisely the personal and imaginative nature of the artist's interventions that lends them their facticity. Like the knowledge, insights, and arguments informing a civil service examination paper, these interventions were peculiar to the person who produced them and, in that sense, were perfectly factual.

So how should such developments have become possible? How did the late Northern Song literati find themselves so at odds with the mainstream norms of their time? At this stage we can hardly avoid considering the impact of the New Policies on the artistic practices of the Northern Song literati. Although the 


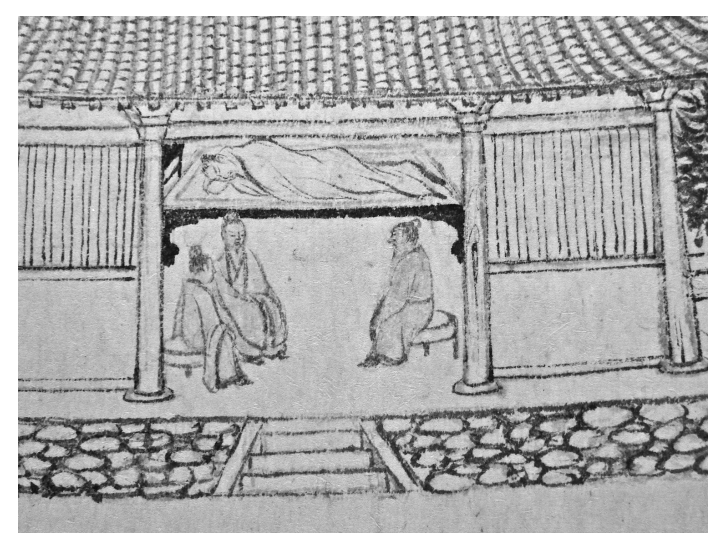

Figure 4: Detail of Figure 3 showing Su Shi simultaneously asleep and conversing with Daoists in his dream. Qiao Zhongchang, Chinese (active late 11th-early 12th century). Illustration to the Second Prose Poem on the Red Cliff, Northern Song Dynasty (960-1127 C.E). Handscroll, ink on paper. Image \& colophon: $12 \times 2473 / 4$ inches $(30.48 \times 629.29 \mathrm{~cm})$. The Nelson-Atkins Museum of Art, Kansas City, Missouri. Purchase: Nelson Gallery Foundation, F80-5.

Photography by the author.

literature on the New Policies is voluminous, ${ }^{29}$ Alfreda Murck's study of literati painting and poetry in that context is of special pertinence here. In one chapter, Murck provides a highly erudite reading of Du Fu's "Autumn Day in Kui Prefecture," a poem in which the master detailed the lives and sufferings of the rural folk under the yolk of oppressive policies. ${ }^{30}$ But Su Shi and his circle had been criminalized precisely for exposing, and criticizing a remarkably similar set of injustices in their own time. Murck documents almost line by line how the injustices recorded in Du Fu's poem resonated for Northern Song literati with their own historical moment, and how creatively they could use Du Fu's work to amplify the political content of their poetry and painting.

$\mathrm{Su}$ Shi for instance, in a poem that was reviewed as evidence during his trial, selected words from Du Fu's "Autumn Day" to end every line of his poem that ended in a rhyme. Note that this was not a $h e$ 和, a poem written to match

29 Peter Bol's classic discussion of the problem is still the best starting point for this matter: Peter Bol, This Culture of Ours (Stanford: Stanford University Press, 1992), 33-75; see also Ronald Egan, Word, Image and Deed in the Life of Su Shi (Cambridge, 1994), 108-133. References to the New Policies' impact on period painting are scattered throughout Yu Hui, Hidden Concerns and Indirect Dissent: Deciphering the 'Spring Festival on the River' Scroll (Beijing: Peking University Press, 2015), [Chinese].

30 Murck, Poetry and Painting, 52-99. 
the rhymes of another poet's work. Rather, Su thoughtfully yet randomly selected particular terms so as to encode specific meanings. A similar strategy could be applied to painting: "The Luoyang exiles appear to have adopted the practice of encoding poetry and painting in ways recognizable only by the cognescenti."31

This strategy was a useful, perhaps necessary response to the unusually oppressive political climate of that moment in Chinese history. Su Shi, in his "Ten-thousand Word Policy Document," noted that the suppression of dissenting views, while common in pre-Song times, had not occurred since the beginning of the dynasty, yet had become standard policy under Wang Anshi 王安石 (1021-1086). ${ }^{32}$ Nor was Su the last cultural icon to observe as much. Zhen Dexiu 真德秀 (1178-1235), an exemplary statesman and Confucian of the Southern Song, fulminated at the outrageous suppression of speech under Wang. Any decent person, he argued, could recognize immediately the rank tyranny of such practices. ${ }^{33}$ Right through to the seventeenth century one can find comparable views. Wang Fuzhi 王夫之 (1619-1692) for one, did not mince words when speaking of Wang's disastrous impact on Emperor Shenzong's reign:

Sometimes people talk big, but their words lack substance/shí; words lacking in substance are a bad sign. A wise monarch will recognize this; he will recognize that man's shortcomings and thus will become alarmed . . . I speak of those whose knowledge is limited but whose plans are big; whose ambition is base and who wish only to sugar coat/shi their incompetence, and who delight in exercising their meanness so as to lock up the mouths of the entire world, thereby flattering their own lies! $!^{34}$ 言有大而無實, 無實者, 不 祥之言也。明主知之, 知其拓落而以是相震 . . . 維知小而圖大, 志陃而欲飾其短者, 樂引取 之, 以鉗天下之口, 而遂其非!

Notice that Wang Fuzhi, in describing Wang Anshi, contrasted shí with shì so as to expose the fact that the Chancellor was not worthy of his charge. For Wang, nothing revealed this more clearly than Wang's suppression of political speech. If the suppression of speech had been normative in late imperial China, as Cold War scholars encouraged us to imagine, its implementation would never have inspired such powerful rebukes from leading intellectuals across the centuries.

It makes more sense to view that moment from the literati perspective: $\mathrm{Su}$ Shi and his fellow exiles had grown up in an empire where public opinion had

31 Murck, Poetry and Painting, 99.

32 Egan, Su Shi: Word, Image, and Deed, 29-38.

33 Wenyuange siku quanshu, Vol. 1418, Shanghai guji chubanshe, 2003, P. 745.

34 Wang Fuzhi, Essays on Song History, In S. Y. Shu (ed.), The Works of Wang Fuzhi (Beijing: Zhonghua Publishing, 1964), 114. 
an impact on policy and where open debate was normative, ${ }^{35}$ yet in their prime they found themselves resisting an intolerant regime inclined to punish adversaries. Alienated and in many ways alone, they turned to culture, the one area where they could reject the court, the prime minister, and social convention, to assert their own, private vision. ${ }^{36}$ Like $\mathrm{Du} \mathrm{Fu}$, they created highly personal works addressing issues of personal integrity and, like Du Fu, they made extensive use of citation to achieve that end. But to make an art historical citation, one would have to mark the historical moment to which the source was linked, and that required juxtaposing styles from different periods utilizing completely different spatial conventions.

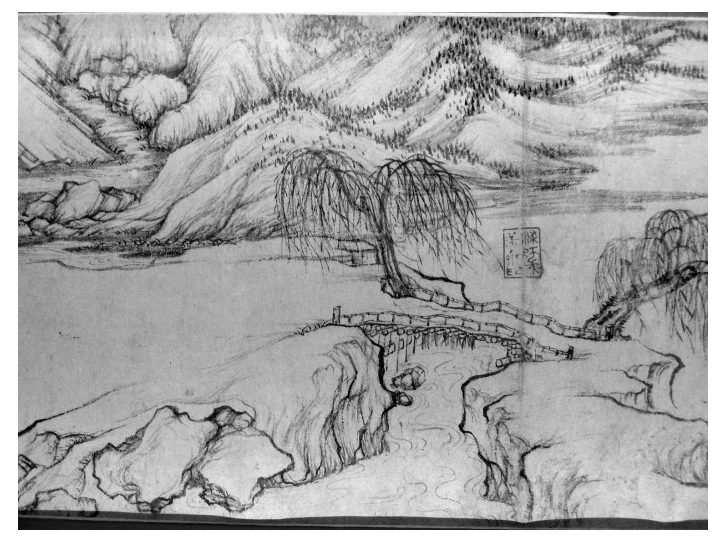

Figure 5: Distant hills in the Dong Yuan style contrasting with Qiao's dry rocks in the foreground. Qiao Zhongchang, Chinese (active late 11th-early 12th century). Illustration to the Second Prose Poem on the Red Cliff, Northern Song Dynasty (960-1127 C.E). Handscroll, ink on paper. Image \& colophon: 12 × $2473 / 4$ inches $(30.48 \times 629.29 \mathrm{~cm})$. The Nelson-Atkins Museum of Art, Kansas City, Missouri. Purchase: Nelson Gallery Foundation, F80-5. Photography by the author.

A good example of this appears in the Qiao Zhongchang scroll (Figures 5 and 6), when the artist cites the rolling hills and "hemp fiber strokes" that were diagnostic of Dong Yuan's 董源 (934-962) style. ${ }^{37}$ Dong Yuan was much admired by Su Shi's circle, Mi Fu 米䒾 (1051-1107) having raised him to the status of a model. The reason was that his painting, in Mi's view, avoided all artifice and

35 Egan citing Su Shi, Su Shi, Word, Image, and Deed, 39.

36 This argument derives from an important insight first developed by Peter Bol, This Culture of Ours (Stanford: Stanford University Press, 1992), 59-66; 73-74.

37 Powers, “Temporal Logic," 759-761. 


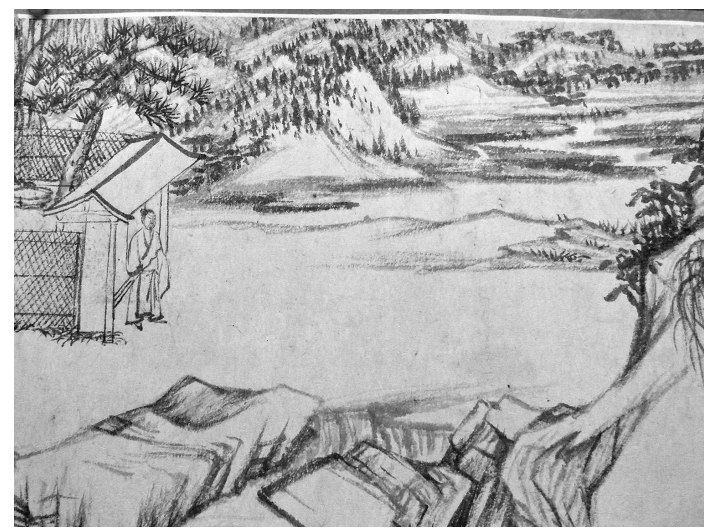

Figure 6: Distant hills in the Dong Yuan style beyond the gate to Su Shi's home. Qiao Zhongchang, Chinese (active late 11th-early 12th century). Illustration to the Second Prose Poem on the Red Cliff, Northern Song Dynasty (960-1127 C.E). Handscroll, ink on paper. Image \& colophon: $12 \times 2473 / 4$ inches $(30.48 \times 629.29$ cm). The Nelson-Atkins Museum of Art, Kansas City, Missouri. Purchase: Nelson Gallery Foundation, F80-5. Photography by the author.

painterly skill. Rather than "naturalistic" ziran, he described Dong's work as "natural and authentic" tianzhen 天真. ${ }^{38}$

Recall that Du Fu's poetry had inspired similar epithets, for these were core literati values. Therefore, within the logic of poetic citation, Dong Yuan's style could serve as metonymy for those same qualities. In his handscroll, Qiao appears to be hinting that $\mathrm{Su} \mathrm{Shi}$, though exiled and a criminal, remained natural and authentic, for Dong Yuan hills appear outside Su's yard twice in the painting, and these are the only times Dong's style is referenced in the entire work. As with literati references to Du Fu's critical poetry, only the cognoscenti would recognize the meaning encoded within the style.

One might inquire, if the literati rejected the horizon and other technical tricks of naturalistic picturing, and moreover were using style to encode specific terms such as "natural" and "genuine," why did they not adopt a generalizing style like that of medieval art (East or West), or the poster art of modern times? The answer is that, unlike the conditions giving rise to those styles, facts and time remained key elements of the literati ethos. Their citations would make no sense except as tokens of specific moments in historical time. More critically still, the facts they employed to make their pictorial arguments were

38 Mi Fei (1051-1107), Hua shi, in Meishu congshu, series II, volume 9:11. 
their own personal actions, sweeps of the brush or whimsical interventions that acquired meaning only in relation to the cultural conventions they flaunted. Ironically, it was those conditions that allowed these men so boldly to challenge pictorial and literary practice at a time when they could not do so in the political realm.

\section{References}

Bachhofer, Ludwig, A Short History of Chinese Art (New York, 1946).

Bai Juyi, Ji hua (A Record of Painting), Zhang Chunlin 张春林 ed., Baijuyi quanji (Collected works of Bai Juyi) (Beijing: Zhongguo wenshi chubanshe, 1996), 755-756.

Bai Juyi, "Yi fengjian, lun junxian (against feudalism and for salaried administration)" in Zhang Chunlin张春林 ed., Baijuyi quanji (Collected works of Bai Juyi) (Beijing: Zhongguo wenshi chubanshe, 1996), 1044-1045.

Bai Juyi, "Yu yuanjiu shu" (A Letter for Yuan Zhen), in Zhou Shaoliang, ed., Quan tangwen xinbian, (Collected essays from the Tang dynasty), Vol. 3, No.3 (Changchun: Jilin wenshi Press, 2000), 7622.

Barnhart, Richard, “Li Kung-lin's Use of Past Styles," in Artists and Traditions: Uses of the Past in Chinese Culture, ed. Christian F. Murck (Princeton, NJ: Princeton University Press, 1976), 51-72.

Bol, Peter, "Whither the Emperor: Emperor Huizong, the New Policies, and the Tang-Song Transition" The Journal of Song-Yuan Studies 31 (2001), 103-134.

Bol, Peter, This Culture of Ours (Stanford: Stanford University Press, 1992).

Bryson, Norman, Word and Image: French Painting of the Ancien Regime (Cambridge, 1980). Egan, Ronald, Word, Image and Deed in the Life of Su Shi (Cambridge, 1994).

Harrist, Robert E., Painting and Private Life in Eleventh-Century China: Mountain Villa by Li Gonglin (Princeton, N): Princeton University Press, 1998).

Li Shu李樹, Zhongguo keju shihua (A history of China's civil service examination) (Jinan: Qilu shushe 2007).

Liu Zongyuan (773-819), ‘Fengjian lun’, in Lü Ch’ing-fei 吕晴飞, ed., Liu Zongyuan sanwen, 3 vols., (Taipei, World publishing house, 1994), I:23-32.

Mi Fu (1051-1107), Hua shi (A History of painting), in Meishu congshu, series II, volume 9: 11.

Murck, Alfreda, Poetry and painting in Song China: the subtle art of dissent (Cambridge: Cambridge University Press, 2000).

Powers, Martin, “Imitation and Reference in China's Pictorial Tradition," in Wu Hung, ed., Reinventing the Past: Archaism and Antiquarianism in Chinese Art and Visual Culture (Chicago: Art Media Resources, 2010), 103-126.

Powers, Martin, "Picturing Time in Song Painting and Poetry", in Joseph Lam et. al., eds., The Senses of the City: Perceptions of Hangzhou and Southern Song China, 1127-1279 (Hong Kong: Hong Kong University Press, 2016), 55-72.

Powers, Martin, "Recurrent dialogues in the history of Chinese and English garden design," in Malcolm Baker and Andrew Hemingway, eds., Art as Worldmaking: Critical Essays on Realism and Naturalism (Manchester: Manchester University Press, 2019), 115-127. 
Powers, Martin, China and England: the Preindustrial Struggle for Justice in Word and Image (London: Routledge, 2018).

Powers, Martin, “The Temporal Logic of Citation in Chinese Art," Art History, vol. 37, no. 4 (September, 2014), 745-763.

Qu Chaoli, Songdai difangzhengfu minshi shenpan zhineng yanjiu (The function of civil courts in local government in Song times) (Chengdu: Bashu Shudian, 2003), 16.

Shen Kuo, Mengxi bitan (Notes from the stream of dreams), vol. 3 (Yangzhou: Guangling shushe, 2003).

Strassberg, Richard, trans. and annot., Inscribed Landscapes: Travel Writing from Imperial China (Berkeley: University of California Press, 1994).

Wang Fuzhi, Song lun (Essays on Song History), In S. Y. Shu (ed.), Wang Fuzhi zhi zhuzuo (The Works of Wang Fuzhi) (Beijing: Zhonghua Publishing, 1964).

Yu Hui, Yinyou yu qujian: qingmingshanghetu jiemalu (Hidden Concerns and Indirect Dissent: Deciphering the 'Spring Festival on the River' Scroll) (Beijing: Peking University Press, 2015). 